\title{
Recent US human gene therapy patents
}

\author{
Breffni Baggot
}

Patent \# Subject

5,703,056 Noninvasive imaging of gene transfer: A method of detecting gene transfer to and expression in a target tissue of a host subject.

5,703,055 Generation of antibodies through lipid-mediated DNA delivery: A method for delivering an isolated polynucleotide to the interior of a cell in a vertebrate.

5,702,384 Apparatus for gene therapy: A pulse voltage is applied to needle cannulas to form a pore in the surface of the human living cell upon application of the pulse voltage. The gene is transferred into the human living cell through the pore.

5,693,536 Gene therapy with MCC: Detection of the alteration of wild-type MCC genes in tumor tissues, and restoration of function of MCC gene product.

$5,688,675$ In vitro packaging of adeno-associated virus DNA: DNA packaged into AAV particles is not limited by the size constraints characteristic of in vivo packaged AAV particles.

5,686,278 Methods for enhanced retrovirus-mediated gene transfer: Increased efficiency of transduction of hematopoietic cells by retroviruses includes infecting the cells in the presence of fibronectin or fibronectin fragments.

5,686,263 Method for enhancing gene expression: Introducing into cell a second nucleic acid sequence (homologous to a first endogenous sequence) and a third nucleic acid sequence that encodes a heterologous gene.

5,681,735 Transcription control element for increasing gene expression in myoblasts: An enhancer element from the upstream region of human myoD and an enhancer element from the upstream region of a quail qmf1.

$5,681,562$ Lymphokine gene therapy of cancer: Autologous fibroblasts genetically modified to secrete at least one cytokine gene product are used to immunize the patient in a formulation with tumor antigens at a site other than an active tumor site.

$5,677,178$ Cytopathic viruses for therapy and prophylaxis of neoplasia: Preferential generation of replication phenotype in neoplastic cells results in apreferential killing of the neoplastic cells, either directly or by expression of a cytotoxic gene in cells expressing a viral replication phenotype.

$5,674,722$ Genetic modification of endothelial cells: Transduced endothelial cells that have been engineered to express stably maintained genetic material encoding a polypeptide or protein product.

5,670,488 Adenovirus vector for gene therapy: Adenovirus genome from which one or more of the $\mathrm{E} 4$ open reading frames has been deleted, but retaining sufficient $E 4$ sequences to promote virus replication in vitro, and additionally comprising a DNA sequence of interest operably linked to expression control sequences and inserted into said adenoviral genome.

5,665,350 Cell cycle-dependent transplantation and ex vivo gene therapy: Transplantation of quiescent stem cells for transplantation therapy and quiescent transfected stem cells for ex vivo gene therapy.
Assignee

Inventors

Date

Sloan-Kettering Inst. for

Blasberg RG,

Cancer Research (New York) Tjuvajev J

Wisconsin Alumni Research

Found. (Madison, WI),

Vical Inc. (San Diego, CA)

Felgner PL, Wolff JA,

Rhodes GH, Malone

Olympus Optical Co., Ltd. (Tokyo)

RW, Carson, DA

Umeyama K,

Ogasawara T, Koda $\mathrm{K}$

Yoshino K,

Watanabe $\mathrm{K}$

Johns Hopkins Univ.

(Baltimore, MD), Univ. of

Utah (Salt Lake City, UT),

The Cancer Inst. (Tokyo)

Research Found. of

State Univ. of New York

(Stony Brook, NY)

Indiana Univ. Found.

(Bloomington, IN)

Vogelstein B, Kinzler $\mathrm{KW}$, White R,

Nakamura $Y$

Zhou X, Muzyczka N, 11/18/97 $\mathrm{Ni}$ T, Zolotukhin S

Williams DA, Patel, VP 11/11/97

Genentech Inc.

(S. San Francisco, CA)

Fox Chase Cancer Ctr.

(Philadelphia, PA)

Sidney Kimmel Cancer

Ctr. (San Diego, CA)

Onyx Pharmaceuticals

(Richmond, CA)

Wurm FM

Emerson CP

$10 / 28 / 97$

Goldhamer DJ

Sobol RE, Gage FH,

$10 / 28 / 97$

Royston I, Friedman T,

Fakhrai $\mathrm{H}$

McCormick F

$10 / 14 / 97$

Somatix Therapy (Alameda, CA), Whitehead Institute

Mulligan RC, Cohen LK, 10/7/97 Rafield LF, Birinyi LK, (Cambridge, MA), Brigham \& Womens Hosp. (Boston, MA), Howard Hughes Med. Inst. (Bethesda, MD), New England Med. Ctr. Hospitals (Boston, MA)

Genzyme Corp.

(Framingham, MA)

Gregory RJ,

$9 / 23 / 97$

Armentano D,

Couture LA, Smith AE

Univ. of Massachusetts

Quesenberry PJ

$9 / 9 / 97$
(Worcester, MA)

Compiled by Breffni Baggot, an intellectual property lawyer based in Manchester, CT (info@biotechlawyer.com). 